\title{
PI3K/MTOR Pathway Mutation
}

National Cancer Institute

\section{Source}

National Cancer Institute. PI3K/MTOR Pathway Mutation. NCI Thesaurus. Code C137953.

A change in the sequence of one or more genes that are involved in the phosphatidylinositol 3 kinase (PI3K) and mammalian target of rapamycin (mTOR) signaling pathway. 